\title{
The effect of pulse welding parameters on weld geometry of boron steel using low power fibre laser
}

\author{
K.I. Yaakob, M. Ishak* and S.R.A. Idris \\ Faculty of Mechanical Engineering, Universiti Malaysia Pahang, \\ 26600 Pekan, Pahang, Malaysia, \\ Phone: +6094246235; Fax: +6094246222 \\ *Email: mahadzir@ump.edu.my
}

\begin{abstract}
Demands of tailored weld blank application on press hardened materials such as boron steel have given interest in the process parameter study of laser welding. The pulse wave mode of laser welding produces high peak power, replacing the continuous wave mode which could lead to wider applications. Due to complications on the process parameter of PW mode, the study of parameter effect is needed. In this paper, the effect of PW welding parameters on weld geometry of boron steel using Fibre laser is presented. Pulse overlap $(\mathrm{PO})$, peak power (PP), pulse duration (PD) and pulse repetition rate are the common process parameters for PW mode used in this study. The bead on plate welding was conducted on uncoated boron steel and observation on width and depth of penetration was done. Based on the results, the higher PO produced deeper penetration and also a bad weld appearance. The effective pulse energy and effective peak power density were the result of the actual condition in pulse seam weld related with overlapping index generated from PO condition. The PP and PD were the related parameters that affected the energy of the beam, giving a significant effect on weld width and penetration. The energy of the beam showed the significance on weld geometry in low peak power laser application and the value will increase with the increase of PD. In contrast, PRR had no significant effect on weld geometry. The constant pulse overlap parameter produced constant energy applied for each pulse which led to no effect on weld geometry.
\end{abstract}

Keywords: Boron steel; Fibre laser; laser welding; welding parameters.

\section{INTRODUCTION}

The usage of advance high strength Steel in automotive industry has become more favourable due to its properties, especially boron steel which is also known as press hardened steel. The transformation properties after hot press forming process is desirable in car body requirement in safety and also lightweight with low cost of replacing the usage of high strength steel (HSS) material [1-7]. In addition, the invention of tailored weld blank (TWB) technology contributes almost $25 \%$ of weight reduction due to optimisation of reinforcement [8-11]. Thus, the application of boron steel in TWB technology has garnered the interest of researchers in recent years to enhance the performance in application. The joining method for TWB parts has high potential using laser welding due to its deep penetration, high speed, and small heat affected zone (HAZ), especially by using Fibre laser [12-22]. Previously, a few studies on TWB application on AHSS material including boron steel have been conducted using continuous wave $(\mathrm{CW})$ mode. 
This welding mode is favourable in industrial usage due to its straightforward processing parameter such as peak power, welding speed and focus position [11, 22-30]. However, the high power of $\mathrm{CW}$ laser source is required to satisfy the penetration for thicker materials. Pulse wave mode (PW) is another option in deep penetration welding with using low power laser source. This welding mode requires low heat input compared to CW welding mode to achieve the same penetration [31]. By utilising the PW mode, the seam weld can be produced, known as the series of overlapping welding spot. Combination of the main process parameters such as peak power (PP), pulse duration (PD), pulse repetition rate (PRR) and pulse overlap (PO) related with pulse energy (E) and peak power density (PPD) in overlapping seam weld leads to complication in parameter optimisation. A lot of studies were done on the effect of PW welding mode parameters.

The parametric analysis of pulsed seam welding using Nd:YAG laser was done by Tzeng, who stated that longer pulse duration in PW mode parameter provided longer heating effect and increased the penetration [32]. Otherwise, the shorter PD with high welding speed led to shallow penetration known as conduction mode welding. However, by decreasing the welding speed while increasing the overlap percentage, the uniformity of weld dimension depended on PD. In contrast with the finding from Fuerschbach \& Eisler [33], the short duration pulses resulted in greater weld penetration depth and melted volume compared to long duration at the same net energy. It showed that the application of spot weld and seam weld using PW mode produced a contradictory effect of parameters. The weld metal microstructural characteristics in PW mode used in car production was conducted by Malekghaini [34] using Nd:YAG laser. He found that the combination of parameters such as E, PD, PRR and welding speed (v) can determine the welding mode, either conduction or keyhole by introducing the cumulative factor, effective peak power density (EPPD) by taking into account the overlapping index (F). The equations of PO, F and EPPD are shown in Eq. (1), Eq. (2) and Eq. (3) respectively.

$$
\begin{gathered}
P O=1-\frac{v}{B_{d} \times P R R} \\
F=\frac{1}{1-P O} \\
E P P D=F \times P P D
\end{gathered}
$$

where $B_{d}$ is known as beam diameter and $v$ is the welding speed. He stated that the 2000 $\mathrm{W} / \mathrm{mm}^{2}$ of PPD and high travel speed produced high cooling rate and the nature of thermal effects of the next pulse was on the previous weld spot. Otherwise, for the PPD value lower than $1700 \mathrm{~W} / \mathrm{mm}^{2}$, the $70 \%$ of overlapping was required. His further research in 2008 on the melting ratio in overlap pulsed laser stated that the E had a stronger effect on melting in comparison with PD, v and PRR [35]. Thus, he introduced the effective pulse energy (EPE) with relation to $F$ as shown in Eq. (4). This equation was developed to predict the actual energy input to material per unit area in order to identify the melting ratio in overlapping pulse welding.

$$
E P E=F \times P
$$

The authors also found that the overlapping of pulse helped in keyhole formation due to the preheat effect. Tadamalle et al. [36] added that the EPE was used in their research on processing parameters on weld pool geometry and duty cycle. Similar, 
increasing the power input which was directly proportional to the increasing EPPD value will promote spattering and lead to reduction in strength of weld joint. They also stated that EPE is a key factor for assessing the mechanical strength of weld joint. In advance, PW mode can also be applied by using low power laser source to achieve similar penetration of several kilowatts of CW mode laser power. The study of PW welding mode by using low power Fibre laser has been conducted by Ascari and Fortunato [37]. Similar to the finding from Tadamalle et al. [36], the high PP and PPD values led to the ablation phenomena and ejection of molten metal from the molten pool. However, with limited peak power output of low power laser, the increment of pulse duration and slow welding speed led to good penetration and weld bead with low aspect ratio.

Based on the previous studies, the complications on PW parameters on seam welding have been given more attention and less focus was given on specific materials. Further study on the specific material is needed for implementation on specific applications. With implementation of low power laser, the study will lead to a wide application in lowering the initial cost of production. Thus, the objective of this study is to identify the effect of PW mode parameters on weld geometry of boron steel by using low power Fibre laser. The PP, PD and PRR were the main selected parameters and the observation on weld width and penetration was conducted.

\section{METHODS AND MATERIALS}

\section{Experimental Set Up}

The thickness of 22MnB5 was $1.6 \mathrm{~mm}$ used in this experiment. The material composition is shown in Table 1. The Al-Si coating on the specimen surface was removed before bead on plate (BOP) welding because this layer has a higher melting point compared to boron steel and will reduce the penetration by avoiding energy absorption into the material. The pulse mode of IPG YLM-QCW Fibre laser machine which has a maximum peak power of up to $2 \mathrm{~kW}$ is shown in Figure 1. The fixed parameter setup is shown in Table 2. There are four sets of experiment to determine the effect of pulse overlap (PO), peak power $(\mathrm{PP})$, pulse duration (PD) and pulse repetition rate. The range of parameter was selected based on the minimum and maximum values of laser machine capability. The parameter range for pulse overlap was 50 - $90 \%$, peak power was 0.2 to $1.8 \mathrm{~kW}$, pulse duration was $1-7 \mathrm{~ms}$ and pulse repetition rate was $10-50 \mathrm{~Hz}$. The wider range of parameter provided better observation on weld geometry behaviour. The reference parameters for pulse overlap, peak power and pulse duration were $60 \%, 1.4 \mathrm{~kW}$ and $1 \mathrm{~ms}$ respectively. However, pulse repetition rate value was different for each set of experiment according to the duty cycle capability. The pulse overlap value and various welding speed values were calculated. The combination of variable parameters is shown in Table 3 . Three samples of cross section were prepared for each specimen. The sample was mounted, ground, polished and etched using $2 \%$ of Nital solution. The measurements of weld geometry on width and depth of penetration were taken using an optical microscope with a measurement software.

Table 1. 22MnB5 element compositions.

\begin{tabular}{ccccccccc}
\hline Composition \% & $\mathrm{C}$ & $\mathrm{Si}$ & $\mathrm{Mn}$ & $\mathrm{P}$ & $\mathrm{S}$ & $\mathrm{Cr}$ & $\mathrm{Ni}$ & $\mathrm{B}$ \\
\hline Boron Steel & 0.26 & 0.30 & 1.24 & 0.016 & 0.003 & 0.20 & 0.016 & 0.004 \\
\hline
\end{tabular}




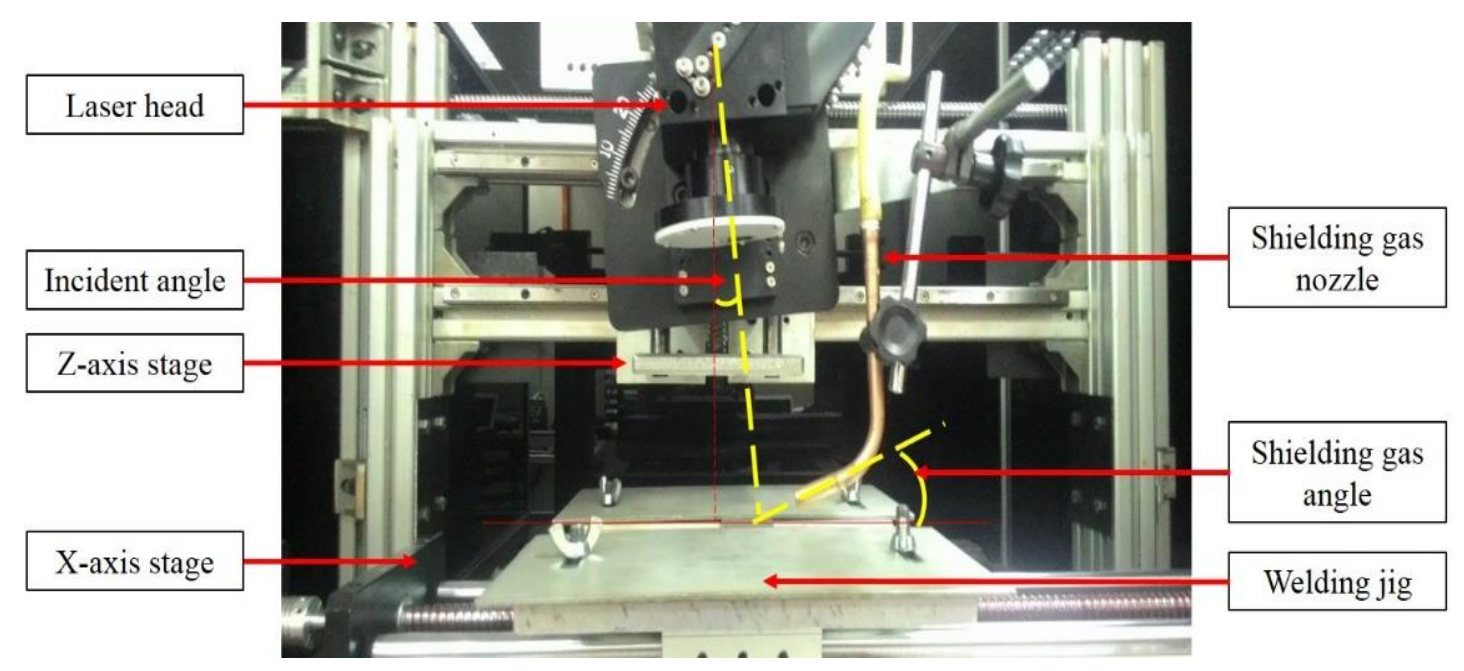

Figure 1. Experimental setup.

Table 2. Fix parameters setup.

Parameter setup for experiment

Focal position $\quad$ Focused at $10 \mathrm{~mm}$ below the surface of material

Beam diameter $0.4425 \mathrm{~mm}$

Shielding gas Argon gas side blown at $15 \mathrm{~L} / \mathrm{min}$ using $6 \mathrm{~mm}$ of nozzle tip diameter at $20^{\circ}$ of angle and $30 \mathrm{~mm}$ distance from the beam

Incident angle $\quad 5^{\circ}$ from the laser head

Table 3. Variable parameters setup.

\begin{tabular}{|c|c|c|c|c|c|}
\hline $\begin{array}{c}\text { Sets of } \\
\text { experiment }\end{array}$ & $\begin{array}{c}\text { Peak Power } \\
\qquad(\mathrm{kW})\end{array}$ & $\begin{array}{c}\text { Pulse } \\
\text { Duration } \\
(\mathrm{ms})\end{array}$ & $\begin{array}{c}\text { Pulse } \\
\text { Repetition } \\
\text { Rate }(\mathrm{Hz})\end{array}$ & Energy $(\mathrm{J})$ & $\begin{array}{l}\text { Welding } \\
\text { speed } \\
(\mathrm{mm} / \mathrm{s})\end{array}$ \\
\hline $\begin{array}{l}\text { Pulse Overlap } \\
\text { (PO) }\end{array}$ & 1.4 & 1 & 50 & 1.4 & $\begin{array}{l}11,8.85, \\
6.64,4.43, \\
2.21\end{array}$ \\
\hline $\begin{array}{l}\text { Peak Power } \\
\text { (PP) }\end{array}$ & $\begin{array}{l}0.2,0.4, \\
0.6,0.8, \\
1.0,1.2, \\
1.4,1.6,1.8\end{array}$ & 1 & 10 & $\begin{array}{l}0.2,0.4,0.6 \\
0.8,1.0,1.2, \\
1.4,1.6,1.8\end{array}$ & 1.77 \\
\hline $\begin{array}{l}\text { Pulse } \\
\text { Duration } \\
\text { (PD) }\end{array}$ & 1.4 & $\begin{array}{l}1,2,3,4, \\
5,6,7\end{array}$ & 20 & $\begin{array}{l}1.4,2.8,4.2, \\
5.6,7.0,8.4, \\
9.8\end{array}$ & 3.54 \\
\hline $\begin{array}{l}\text { Pulse } \\
\text { Repetition } \\
\text { Rate (PRR) }\end{array}$ & 1.4 & 1 & $\begin{array}{l}10,20,30 \\
40,50\end{array}$ & 1.4 & $\begin{array}{l}1.77,3.54, \\
5.31,7.08, \\
8.85\end{array}$ \\
\hline
\end{tabular}

\section{RESULTS AND DISCUSSION}

\section{Effect of Pulse Overlap}

Figure 2 shows the effect of PO percentage on weld geometry. No significant difference was observed on weld width when increasing the PO percentage. The small increment of 
width might be due to irregular weld bead formation where the higher percentage of overlap led to the chaos formation of weld bead. The depth of penetration showed a huge increment with the increase of overlap percentage. The keyhole formation occurred at $80 \%$ of PO percentage value with more than 1 of aspect ratio value. This is because effective penetration will increase with the increasing overlap percentage as shown in Figure 3.

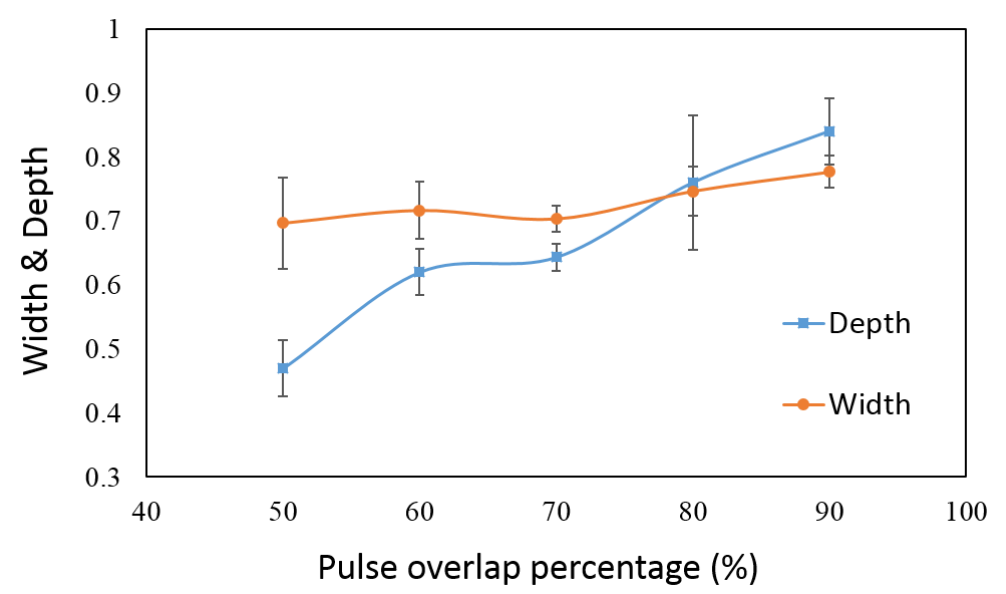

Figure 2. Effect of pulse overlap on width and depth

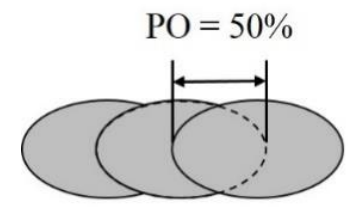

(a)

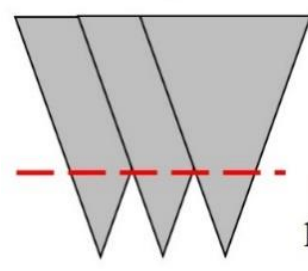

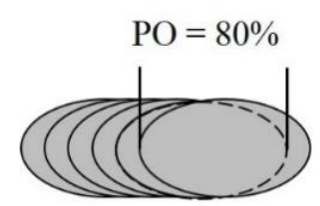

(b)

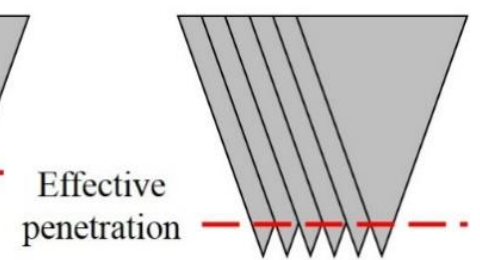

Figure 3. Effective penetration for (a) $50 \%$ of overlap (b) $80 \%$ of overlap

Higher penetration was observed at high PO percentage. This condition exposed the weld bead to the chaos formation and increased the possibility of defect existence such as undercut. However, the lower overlap percentage produced the lower effective penetration and caused the porosity existence. The short period of keyhole opening might trap the porosity inside the molten pool. Besides that, the overlap percentage was also used to indicate the behaviour of reheat, remelt, and resolidification of a portion of the previous spot which has not yet cooled significantly. Thus, it led to the introduction of $F$ value to estimate the real condition on overlapping pulse in the performance factor. From the $\mathrm{F}$ equation, the higher pulse overlap resulted in high $\mathrm{F}$ value. High cumulative factor was obtained by taking into account the $\mathrm{F}$ value resulting in a deeper penetration. Moreover, Sabbaghzadeh has reported that the real transferred PPD and E to the area with overlapping pulse were identified to be higher than the energy that entered into an 
individual pulse [28]. The keyhole formation also helped by overlapping the preheat effect from this phenomena. Similar to the present study, the penetration was increased by increasing the overlap percentage. According to Tzeng, the high PO value is suitable for low E application to produce acceptable welds [38]. The $60 \%$ of overlap was used for PP, PD and PRR experiments resulting in 2.5 of the F value.

\section{Effect of Peak Power}

PP is commonly discussed as the main parameter associated with penetration. The increment of PP will increase the penetration. In the present study, the increments of width and penetration with the increase of PP were almost linear as shown in Figure 4. These increments were related with the PPD and E applied on the specimen. In the real condition of pulse seam welding, EPPD and EPE have been introduced by previous researchers where the higher the value of PP and E applied, the deeper the penetration achieved.

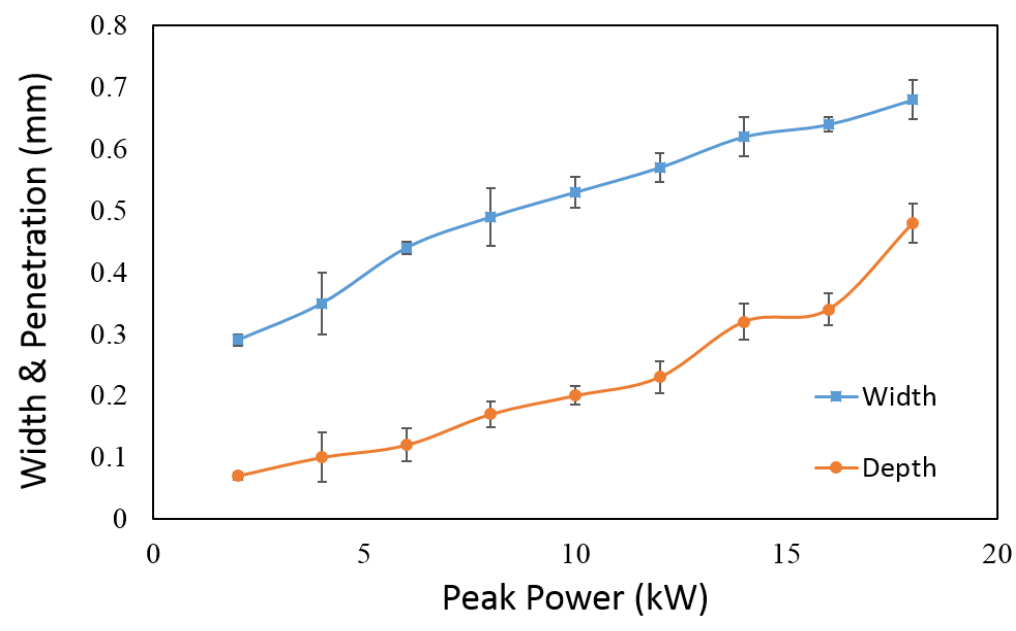

Figure 4. Effect of peak power on width and depth
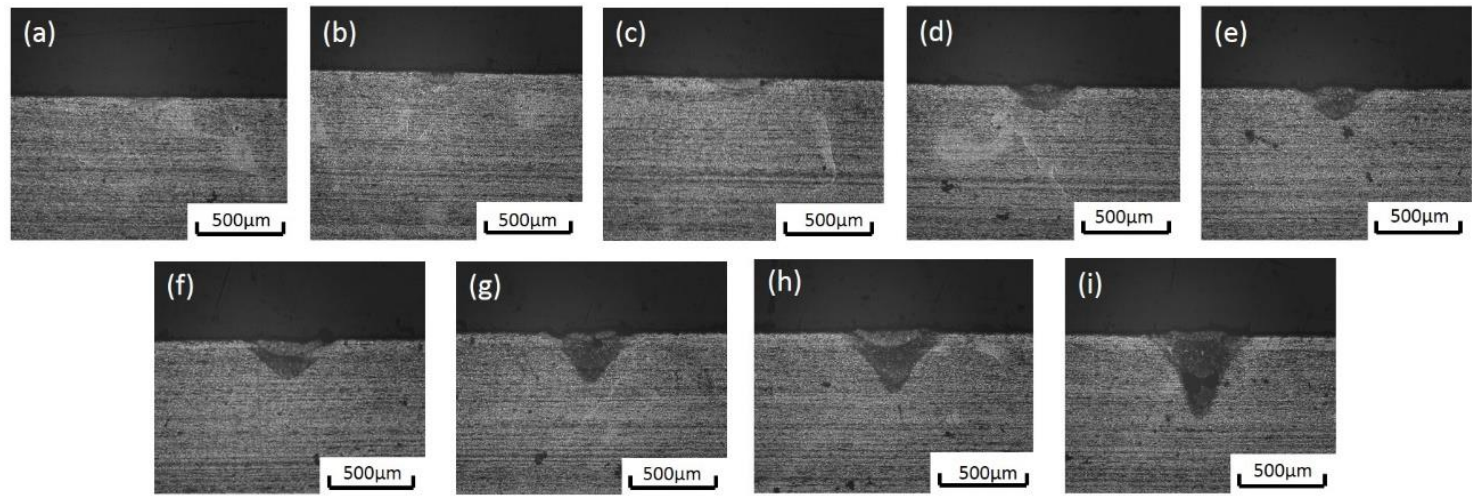

Figure 5. Cross section with increasing peak power (a) $0.2 \mathrm{~kW}$ (b) $0.4 \mathrm{~kW}$ (c) $0.6 \mathrm{~kW}$ (d) $0.8 \mathrm{~kW}$ (e) $1.0 \mathrm{~kW}$ (f) $1.2 \mathrm{~kW}$ (g) $1.4 \mathrm{~kW}$ (h) $1.6 \mathrm{~kW}$ (i) $1.8 \mathrm{~kW}$

The aspect ratio calculated for each peak power value was below 1. It proved that conduction mode has occurred. Figure 5 shows clearly the penetration pattern which supported the result of conduction mode behaviour. However, it can be observed that the penetration increased drastically along with the depth-to-width aspect ratio at $1.8 \mathrm{~W}$ of 
PP. The drastic increment showed that the value of PPD started to form the key hole. This parameter combination produced $1.8 \mathrm{~J}$ of $\mathrm{E}$ which was not sufficient to melt the material and create deeper penetration [39].

\section{Effect of Pulse Duration}

Low power laser has a limited value of the PP. The PD is the only parameter which can increase the E value with constant PP value. However, the value is limited on the capability of the duty cycle for laser source. The effect of PD on width and penetration is shown in Figure 6. The width and penetration were increased with the increase of PD value. At $3 \mathrm{~ms}$, it was observed that the depth value was higher than width value which indicated that the value of aspect ratio was higher than 1 . It showed the starting point of keyhole formation. The increment of aspect ratio continued with the increasing PD value, also indicating that the keyhole formation was stable. However, the ratio of the width of the bottom (root) weld seam to the width of the top (face) weld seam value must be larger than 0.4 to determine a stable formation of keyhole, and less defect and higher tensile strength can be expected [40].

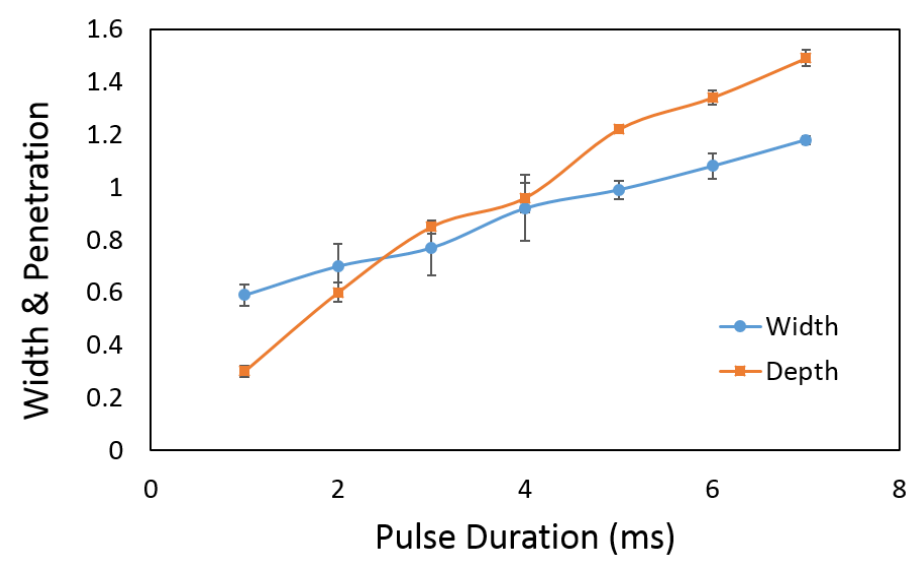

Figure 6. Effect of pulse duration on width and depth.
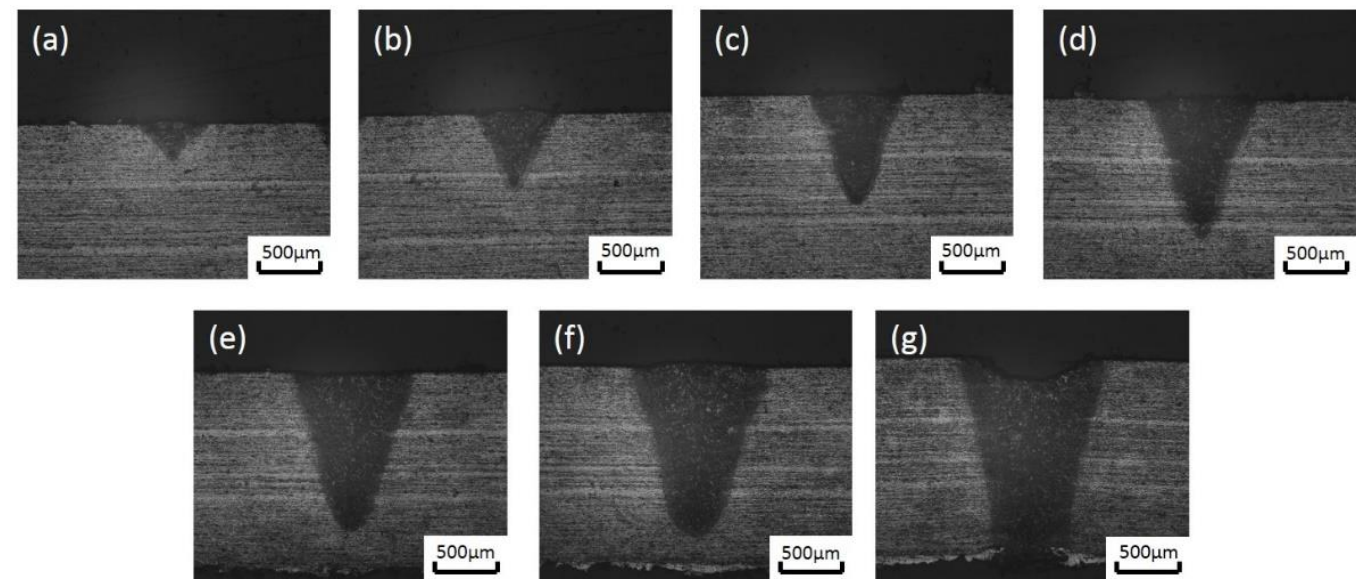

Figure 7. Cross section with increasing pulse duration (a) $1 \mathrm{~ms}$ (b) $2 \mathrm{~ms} \mathrm{(c)} 3 \mathrm{~ms}$ (d) $4 \mathrm{~ms} \mathrm{(e)} 5 \mathrm{~ms}$ (f) $6 \mathrm{~ms}$ (g) $7 \mathrm{~ms}$.

Figure 7 shows cross section with increasing pulse duration. The increment of width and penetration was due to the increment of $E$ value along with PD. PD is the period 
of the laser pulse for each cycle. The longer the time for pulse on, the more the interaction time of the laser beam to reach the workpiece. The energy transfer rate by thermal conduction to the surrounding material also increased. The shorter heating time by low $\mathrm{PD}$ value requires more power pulses and hence more PO value to obtain sound seam weld [38]. Besides, by increasing the interaction time, more heat was conducted to the workpiece, producing a wider molten pool. After solidification of the molten pool, the fusion zone and HAZ area will increase. In real condition of pulse seam welding, EPE is claimed as a key factor of melting ratio calculation which also contributes in positive effect with the interaction time. The present data showed that the increment of interaction time together with EPE led to the increment of width and depth while maintaining the EPPD. The limitation of EPPD value on width and depth by using low power laser machine can be assisted by the EPE factor. Thus, in low power laser application, EPE evaluation is an important geometrical attribution.

\section{Effect of Pulse Repetition Rate}

Figure 8 shows the effect of PRR on width and penetration. It shows that there are no significant changes in width and penetration when increasing the pulse repetition rate from 10 to $50 \mathrm{~Hz}$. This might have happened because there were no changes in PPD and $E$ applied on the workpiece. With the constant value of overlap percentage for each PRR value, F remained constant. In real condition of pulse overlap welding, the constant overlapping index will produce a consistent performance factor on EPPD and EPE. Thus, it will lead to no significant difference in width and penetration with the increasing PRR. In addition, the increment of PRR only influenced the duty cycle of pulse. The duty cycle of pulse increased with the increasing PRR. However, this laser machine was only capable of $10 \%$ of duty cycle only, which might lead to no significant effect on the weld geometry as well.

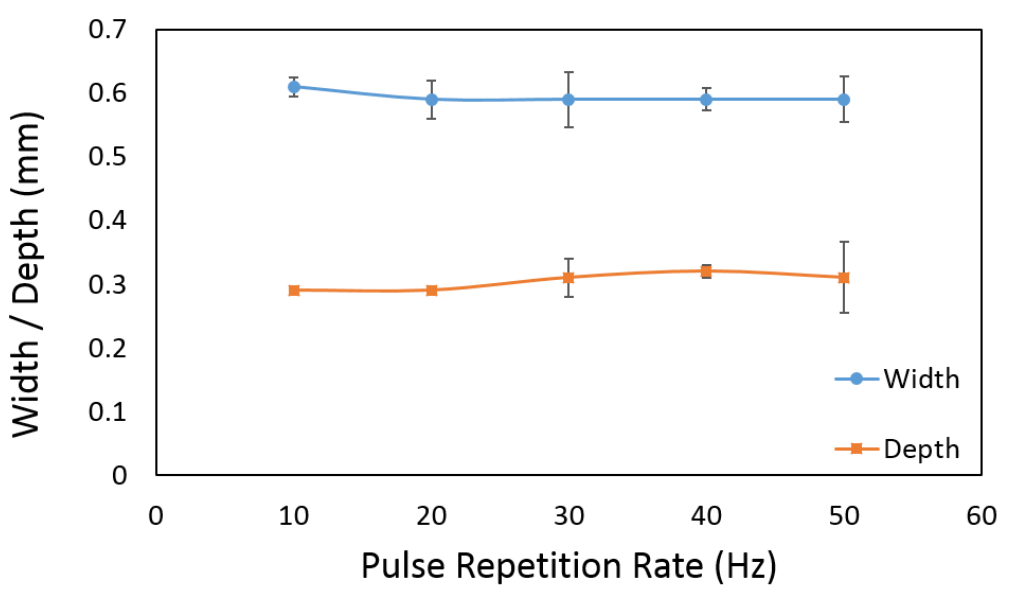

Figure 8. Effect of pulse repetition rate on width and depth

\section{CONCLUSIONS}

This paper deals with overlapping seam welding using low power Fibre laser on boron steel. The effect of process parameters for PW mode of laser welding for PP, PD and PRR was studied. The geometry of BOP welding was observed in terms of width and depth. In particular, the following conclusions can be drawn: 
i) In low power laser application, PD is an important parameter to increase the pulse energy, thus increasing the width and penetration with a limited value of PP.

ii) EPE had the most influential performance factor in real time condition of seam pulse weld using low power laser compared to EPPD due to limitation on PP value.

iii) The influence of PRR in pulse seam welding can be replaced with overlapping factor for simplification in performance factor evaluation.

iv) The relation between parameters can be clearly evaluated by using statistical analysis such as RSM method, illustrated in surface / contour plot and suggested for future works.

\section{ACKNOWLEDGEMENTS}

The author would like to thank the supervisors and technical staffs in Universiti Malaysia Pahang, all of the work within which experiment were conducted. The financial support by Ministry of Education Malaysia through Universiti Malaysia Pahang for Research Grant project no. RDU1403114 is also grateful acknowledged.

\section{REFERENCES}

[1] Gan W, Babu SS, Kaputska N, Wagoner RH. Microstructural effects on the springback of advanced high-strength steel. Metallurgical and Materials Transactions A. 2006;37:3221-31.

[2] Xiaodong Z, Zhaohui M, Li W. Current Status of Advanced High Strength Steel for Auto-making and its Development in Baosteel. Shanghai, China: Baosteel research institute; 2011. p. 1-8.

[3] Chen G, Shi MF, Tyan T. Optimized AHSS Structures for Vehicle Side Impact. SAE International Journal of Materials and Manufacturing. 2012;5:304-13.

[4] Májlinger K, Kalácska E, Russo Spena P. Gas metal arc welding of dissimilar AHSS sheets. Materials \& Design. 2016;109:615-21.

[5] Galán J, Samek L, Verleysen P, Verbeken K, Houbaert Y. Advanced high strength steels for automotive industry. Revista de Metalurgia. 2012;48:118-31.

[6] Kuziak R, Kawalla R, Waengler S. Advanced high strength steels for automotive industry. Archives of Civil and Mechanical Engineering. 2008;8:103-17.

[7] Rossini M, Spena PR, Cortese L, Matteis P, Firrao D. Investigation on dissimilar laser welding of advanced high strength steel sheets for the automotive industry. Materials Science and Engineering: A. 2015;628:288-96.

[8] Uchihara M. Joining technologies for automotive steel sheets. Welding International. 2011;25:249-59.

[9] Merklein M, Johannes M, Lechner M, Kuppert A. A review on tailored blanksProduction, applications and evaluation. Journal of Materials Processing Technology. 2014;214:151-64.

[10] Xu F, Wang C. Dynamic axial crashing of tailor-welded blanks (TWBs) thinwalled structures with top-hat shaped section. Advances in Engineering Software. 2016;96:70-82.

[11] Shah LH, Mohamad UK, Yaakob KI, Razali AR, Ishak M. Lap joint dissimilar welding of aluminium AA6061 and galvanized iron using TIG welding. Journal of Mechanical Engineering and Sciences. 2016;10:1817-26. 
[12] Suder WJ, Williams S. Power factor model for selection of welding parameters in CW laser welding. Optics \& Laser Technology. 2014;56:223-9.

[13] Mei L, Chen G, Jin X, Zhang Y, Wu Q. Research on laser welding of high-strength galvanized automobile steel sheets. Optics and Lasers in Engineering. 2009;47:1117-24.

[14] Bardelcik A, Worswick MJ, Wells MA. The influence of martensite, bainite and ferrite on the as-quenched constitutive response of simultaneously quenched and deformed boron steel - Experiments and model. Materials \& Design. 2014;55:509-25.

[15] Mei L, Yan D, Yi J, Chen G, Ge X. Comparative analysis on overlap welding properties of fiber laser and $\mathrm{CO} 2$ laser for body-in-white sheets. Materials \& Design. 2013;49:905-12.

[16] Assunção E, Quintino L, Miranda R. Comparative study of laser welding in tailor blanks for the automotive industry. The International Journal of Advanced Manufacturing Technology. 2009;49:123-31.

[17] Hong K-M, Shin YC. Prospects of laser welding technology in the automotive industry: A review. Journal of Materials Processing Technology. 2017;245:46-69.

[18] Sharma RS, Molian P. Weldability of advanced high strength steels using an Yb:YAG disk laser. Journal of Materials Processing Technology. 2011;211:188897.

[19] Sharma RS, Molian P. Yb:YAG laser welding of TRIP780 steel with dual phase and mild steels for use in tailor welded blanks. Materials \& Design. 2009;30:414655.

[20] Moon J-H, Seo P-K, Kang C-G. A study on mechanical properties of laser-welded blank of a boron sheet steel by laser ablation variable of Al-Si coating layer. International Journal of Precision Engineering and Manufacturing. 2013;14:2838.

[21] Tang B, Yuan Z, Cheng G, Huang L, Zheng W, Xie H. Experimental verification of tailor welded joining partners for hot stamping and analytical modeling of TWBs rheological constitutive in austenitic state. Materials Science and Engineering: A. 2013;585:304-18.

[22] Hetch J. Fiber lasers-The state of the art. Laser Focus Word2012. p. 1-22.

[23] Moskvitin GV, Polyakov AN, Birger EM. Application of laser welding methods in industrial production. Welding International. 2013;27:572-80.

[24] Kawahito Y, Mizutani M, Katayama S. Investigation of High-Power Fiber Laser Welding Phenomena of Stainless Steel. Transactions of JWRI. 2007;36:11-6.

[25] Selamat NFM, Baghdadi AH, Sajuri Z, Kokabi AH. Friction stir welding of similar and dissimilar aluminium alloys for automotive applications. International Journal of Automotive and Mechanical Engineering. 2016;13:3401-12.

[26] Wor LC, Rahman MM. Stress behavior of tailor-welded blanks for dissimilar metals using finite element method. International Journal of Automotive and Mechanical Engineering. 2015;11:2541-54.

[27] Ishak M, Noordin NFM, Razali ASK, Shah LHA, Romlay FRM. Effect of filler on weld metal structure of AA6061 aluminum alloy by tungsten inert gas welding. International Journal of Automotive and Mechanical Engineering. 2015;11:243846.

[28] Asmara YP, Siregar JP, Shah LH, Tezara C. Experimental investigations on corrosion model of welded 6061 aluminum exposed in $\mathrm{NaCl}$ solution. 
International Journal of Automotive and Mechanical Engineering. 2015;11:26007.

[29] Hussin MH, Che Lah NA. Effects of temperature on the surface and subsurface of Al-Mg-Si welded joints. Journal of Mechanical Engineering and Sciences. 2017;11:2743-54.

[30] Hasan MM, Ishak M, Rejab MRM. A simplified design of clamping system and fixtures for friction stir welding of aluminium alloys. Journal of Mechanical Engineering and Sciences. 2015;9:1628-39.

[31] Assuncao E, Williams S. Comparison of continuous wave and pulsed wave laser welding effects. Optics and Lasers in Engineering. 2013;51:674-80.

[32] Tzeng Y-F. Parametric analysis of the pulsed NdYAG laser seam-welding process. Journal of Materials Processing Technology. 2000;102:40-7.

[33] Fuerschbach PW, Eisler GR. Effect of laser spot weld energy and duration on melting and absorption. Science and Technology of Welding and Joining. 2013;7:241-6.

[34] Malek Ghaini F, Hamedi M, Torkamany M, Sabbaghzadeh J. Weld metal microstructural characteristics in pulsed Nd: YAG laser welding. Scripta Materialia. 2007;56:955-8.

[35] Sabbaghzadeh J, Hamedi MJ, Ghaini FM, Torkamany MJ. Effect of Process Parameters on the Melting Ratio in Overlap Pulsed Laser Welding. Metallurgical and Materials Transactions B. 2008;39:340-7.

[36] Tadamalle AP, Reddy YP, Ramjee E. Influence of laser welding process parameters on weld pool geometry and duty cycle. Advances in Production Engineering \& Management. 2013;8:52-60.

[37] Ascari A, Fortunato A. Nanosecond pulsed laser welding of high carbon steels. Optics \& Laser Technology. 2014;56:25-34.

[38] Tzeng Y-F. Process Characterisation of Pulsed NdYAG Laser Seam Welding. International Journal of Advance Manufacturing Technology. 2000;16:10-8.

[39] Markovits T, Takács J. Edge welding of laminated steel structure by pulsed Nd:YAG laser. Physics Procedia. 2010;5:47-52.

[40] Sinha AK, Kim DY, Ceglarek D. Correlation analysis of the variation of weld seam and tensile strength in laser welding of galvanized steel. Optics and Lasers in Engineering. 2013;51:1143-52. 